University of Nebraska - Lincoln

DigitalCommons@University of Nebraska - Lincoln

\title{
Laboratory Evaluation Of Mosquito Traps Baited With A Synthetic Human Odor Blend To Capture Aedes Aegypti
}

Ivoneide M. Silva

Universidade Federal de Minas Gerais

Alvaro E. Eiras

Universidade Federal de Minas Gerais

Daniel L. Kline

United States Department of Agriculture

Ulrich R. Bernier

University of Florida, ubernier@gainesville.usda.ufl.edu

Follow this and additional works at: https://digitalcommons.unl.edu/usdaarsfacpub

Part of the Agricultural Science Commons

Silva, Ivoneide M.; Eiras, Alvaro E.; Kline, Daniel L.; and Bernier, Ulrich R., "Laboratory Evaluation Of Mosquito Traps Baited With A Synthetic Human Odor Blend To Capture Aedes Aegypti" (2005). Publications from USDA-ARS / UNL Faculty. 950.

https://digitalcommons.unl.edu/usdaarsfacpub/950

This Article is brought to you for free and open access by the U.S. Department of Agriculture: Agricultural Research Service, Lincoln, Nebraska at DigitalCommons@University of Nebraska - Lincoln. It has been accepted for inclusion in Publications from USDA-ARS / UNL Faculty by an authorized administrator of DigitalCommons@University of Nebraska - Lincoln. 


\title{
SCIENTIFIC NOTE
}

\section{LABORATORY EVALUATION OF MOSQUITO TRAPS BAITED WITH A SYNTHETIC HUMAN ODOR BLEND TO CAPTURE AEDES AEGYPTI}

\author{
IVONEIDE M. SILVA, ${ }^{1}$ ÁLVARO E. EIRAS,${ }^{1,3}$ DANIEL L. KLINE, ${ }^{2}$ AND ULRICH R. BERNIER ${ }^{2}$
}

\begin{abstract}
A synthetic blend of chemicals comprising volatiles released by the human body has been shown to be an effective attractant for female Aedes aegypti in olfactometer bioassays with laboratory-reared mosquitoes. We report the laboratory evaluation of Ae. aegypti response to a synthetic blend tested with 4 types of mosquito traps (CDC model 512, CDC model 1012, CFG, and Fay-Prince traps). Aedes aegypti females were attracted significantly by the blend. The higher release rate of attractant $(320.2 \pm 10.71 \mathrm{mg} / \mathrm{h})$ more efficiently attracted mosquitoes than the lower release rate $(42.0 \pm 2.3 \mathrm{mg} / \mathrm{h})$. Although both the Fay-Prince and CFG traps caught higher number of mosquitoes than the other traps, only the CFG trap caught a statistically significant greater number of mosquitoes. The results suggest that the synthetic blend is effective in attracting Ae. aegypti females under controlled laboratory conditions (i.e., a closed system). Further studies are needed to evaluate the efficacy of this blend in baited traps under field conditions.
\end{abstract}

KEY WORDS Aedes aegypti, human odor, mosquito, traps, monitoring

Human bait catches have been reported as the standard and most useful method for collecting host-seeking anthropophilic mosquitoes (Service 1993). Because the sampling method depends on the skills and the relative attraction of the collector, it is highly subjective (Mboera et al. 2000). Moreover, when a living subject is used as bait, there is a risk of getting a disease. Traps baited with specific attractants provide a more consistent monitoring tool for host-seeking pathogen-carrying mosquitoes, obviating the need to expose humans to danger. Several types of traps with different efficacies have been used to trap mosquitoes. The most common mosquito surveillance trap is the Centers for Disease Control and Prevention (CDC) light trap (Sudia and Chamberlain 1962). Nevertheless, unless baited with carbon dioxide, this trap does not efficiently capture diurnal mosquitoes such as $A e$ des aegypti (Linnaeus 1762) because this species is not attracted by incandescent light. The Fay-Prince (Fay and Prince 1970) and counterflow geometry (CFG; Kline 1999) traps have shown some promise for catching diurnal mosquito species.

Although many mosquito species display visual response to distinct objects at a distance of up to $19 \mathrm{~m}$ (Bidlingmayer and Hem 1980), olfactory stimuli from host odors are considered to be the strongest cues for location of hosts for blood meals (Allan et al. 1987, Bowen 1991, Eiras 2001). Volatile chemicals such as $\mathrm{CO}_{2}$, octenol, and acetone

${ }^{1}$ Laboratório de Culicídeos, Depto. Parasitologia, ICB, Universidade Federal de Minas Gerais, Av. Antônio Carlos, 6627, Pampulha, Belo Horizonte, MG, 31.270-901, Brazil.

${ }^{2}$ U.S. Department of Agriculture, Agricultural Research Service, Center for Medical, Agricultural, and Veterinary Entomology, 1600 SW 23rd Drive, Gainesville, FL 32608.

${ }^{3}$ To whom correspondence should be addressed. and less volatile substances such as lactic acid and fatty acids are present on skin as a result of host vertebrate metabolism (Sastry et al. 1980). It has been established that human odor contains volatile chemical substances that increase mosquito attraction in the laboratory (Schreck et al. 1981, Eiras and Jepson 1991, 1994) and in the field (Gillies and Wilkes 1974; Edman 1979). Recently, volatiles released by human skin have been identified (Bernier et al. 1999, 2000, 2002), and blends of these compounds have been evaluated in laboratory olfactometer bioassays against Ae. aegypti females (Bernier et al. 2001, 2003). Because the artificial human odor blend attracted female Ae. aegypti mosquito in laboratory bioassays, we chose to evaluate in a controlled laboratory setting of its use as an attractant for traps to enhance the capture of Ae. aegypti. The work reported herein comprises laboratory and field studies that evaluate the response of female Ae. aegypti to 4 traps baited with 2 releases rates of a synthetic 3-compound blend based on human skin odor.

Laboratory experiments were conducted with $\mathrm{F}_{2}$ to $\mathrm{F}_{4}$ generations of Ae. aegypti from captured wild mosquitoes in the urban area of Belo Horizonte city, Minas Gerais State, Brazil. The mosquitoes were reared in a controlled insectary at $27^{\circ} \mathrm{C}, 70 \%$ relative humidity, and a $12-\mathrm{h}$ photophase. Mosquito larvae were fed with tetramin fish food. Adult mosquitoes were held in cages $(30 \times 30 \times 30 \mathrm{~cm})$ and fed on $10 \%$ sugar solution. Female mosquitoes were allowed to feed on an immobilized quail once a week to maintain the colony. Experiments were performed with 10-12-d-old females that had not been fed blood. The blend comprised $480 \mathrm{ml}$ of acetone, $0.96 \mathrm{~g}$ of L-lactic acid, and $10 \mathrm{ml}$ of dimethyl disulfide (Bernier et al. 2001). This blend was placed into 2 types of vials: 1 type had a 5- 
$\mathrm{mm}$ internal diameter (i.d.) and the other had a 13 $\mathrm{mm}$ i.d. The release rate of the blend was measured on an analytical balance (Sartorius BP221S, Germany) hourly by recording the weight lost from each vial containing the blend. Measurements were taken over a period of $12 \mathrm{~h}$ while maintaining a temperature of $27.1 \pm 0.2^{\circ} \mathrm{C}$ and a relative humidity of $60.4 \pm 0.7 \%$. Five replicates were made for each vial size used. The mean release rate was $41.9 \pm$ $2.3 \mathrm{mg} / \mathrm{h}$ for the $5-\mathrm{mm}-\mathrm{i} . \mathrm{d}$. vial and $320.2 \pm 10.7$ $\mathrm{mg} / \mathrm{h}$ for the 13-mm-i.d. vial.

Four types of mosquito traps were evaluated: 1) CDC model 512 (John W. Hock Company, Gainesville, FL; Sudia and Chamberlain 1962), 2) CDC model 1012 (John W. Hock Company), 3) CFG (American Biophysics Corporation, East Greenwich, RI; Kline 1999), and 4) Fay-Prince trap (John W. Hock Company; Fay and Prince 1970). The CDC mosquito traps were operated without light. The CDC and Fay-Prince traps were powered by a $6-\mathrm{V}$ rechargeable battery, and the $\mathrm{CFG}$ used a $12-\mathrm{V}$ rechargeable battery. Preliminary tests with a smoke plume generated by hydrochloric acid and ammonium hydroxide (Eiras and Jepson 1991) in each trap type identified optimum location for vials containing attractant (Fig. 1). Each trap was evaluated individually in a screened cage $(2.0 \mathrm{~m}$ high $\times 2.5 \mathrm{~m}$ wide $\times 2.8 \mathrm{~m}$ deep) within a room maintained at $25 \pm 1{ }^{\circ} \mathrm{C}$ and $55 \pm 5 \%$ relative humidity. Each trap was elevated such that the lowest part was $1.0 \mathrm{~m}$ above the floor at the center of the cage. The mosquito response to low $(42.0 \pm 2.3 \mathrm{mg} / \mathrm{h}, n$ $=6)$ and high (320.2 $\pm 10.7 \mathrm{mg} / \mathrm{h}, n=8)$ release rates of the attractant blend for each trap model was tested. Unbaited traps were tested as the controls ( $n$ $=2$ ).

For each test, 20 Ae. aegypti female were selected by an airflow apparatus that allowed trapping of primarily female mosquitoes seeking a blood meal (Posey and Schreck 1981). Test mosquitoes were not allowed to feed on sugar for at least $3 \mathrm{~h}$ before each experiment. Preliminary studies showed that 20 min per test was the ideal duration for each experiment (IMS, unpublished data). The experiment started after releasing the mosquitoes at 1 corner of the screened cage with 1 mosquito trap model baited either with the attractant blend or left as an unbaited control. During the experiment, the human observer remained outside of the room to avoid possible introduction of bias from chemical and visual cues. After the 20-min period, the number of trapped mosquitoes were counted, and those that did not respond were removed from the screened cage by a vacuum cleaner (Model APAC, Arno S.A., São Paulo, Brazil). The proportions of mosquitoes caught were arcsine transformed. Comparisons of means were done by Student's $t$-test, analysis of variance (ANOVA), and Tukey test (Wilinson et al. 1998).

Traps evaluated without attractant (control) collected varying numbers of mosquitoes. The CDC-
512 and CDC-1012 traps each caught $<3 \%$ of the released mosquitoes, whereas the Fay-Prince and CFG traps collected 28.3 and $24.7 \%$, respectively. When baited with attractant at the lower release rate, the CDC-1012 and CFG traps collected a significantly higher percentage of Ae. aegypti than the control ( $t$-test, $P<0.05$; Fig. 2 a). The percentage of mosquitoes caught in trap types baited with the lower attractant release rate varied significantly compared with each other (ANOVA F $=4.523, \mathrm{df}$ $3,20, P<0.05$, Tukey test). The CFG collected significantly more females than the CDC-512, whereas the number of mosquitoes collected by Fay-Prince and CDC-1012 were not significantly different from CFG and CDC-512 (Fig. 2a). Traps baited with synthetic attractants at the higher release rate increased significantly the percentage of mosquitoes caught compared with the same trap without attractants ( $t$-test, $P<0.05$; Fig. 2 b). The percentage of mosquitoes caught in baited traps varied between the trap types. The CFG trap caught the highest percentage of mosquitoes $(72.25 \%)$, and the CDC-1012 caught the smallest percentage $(23.39 \%$ ) (ANOVA $F=20.627$, df 3,27, $P<$ 0.001 , Tukey test; Fig. 2b). The mean response of mosquitoes was higher in the tests with the higher release rate than those with the lower release rate. However, this difference was not statistically significant ( $t$-test, $P>0.05$ ).

Synthetic blend odors are significantly attractive to Ae. aegypti evaluated under laboratory conditions in which temperature and humidity are controlled and human competition is absent. Attractant released at a higher rate collected mosquitoes more efficiently than attractant released at a lower rate. The Fay-Prince and CFG traps resulted in the highest number of mosquitoes caught, but only the CFG trap caught significantly more female Ae. aegypti than the other types of traps. The superiority of the Fay-Prince trap compared with the CDC trap for collecting Ae. aegypti has been reported by Service (1993). The ability of the CFG trap to more efficiently trap mosquitoes compared with other traps was demonstrated by Kline (1999) and Mboera et al. (2000). Traps based on the updraft principle, such as the CFG, enhance mosquito collection (Service 1993). The upflow design increases the likelihood of mosquito capture because when mosquitoes encounter the air stream, they attempt to escape by vigorous flight activity in an upward flight movement (Wilton and Fay 1972). The CFG trap provides an attractant plume that has a high concentration of attractant at the trap entrance (Kline 1999). Preliminary tests with a smoke plume confirmed that a high concentration of attractant stayed at the trap entrance. The unbaited FayPrince and CFG traps collected female Ae. aegypti. Canyon and Hii (1997) found similar results with the bidirectional Fay trap design. They observed that the mean catch of an unbaited trap was higher than one baited with lactic acid, octenol, or both. 

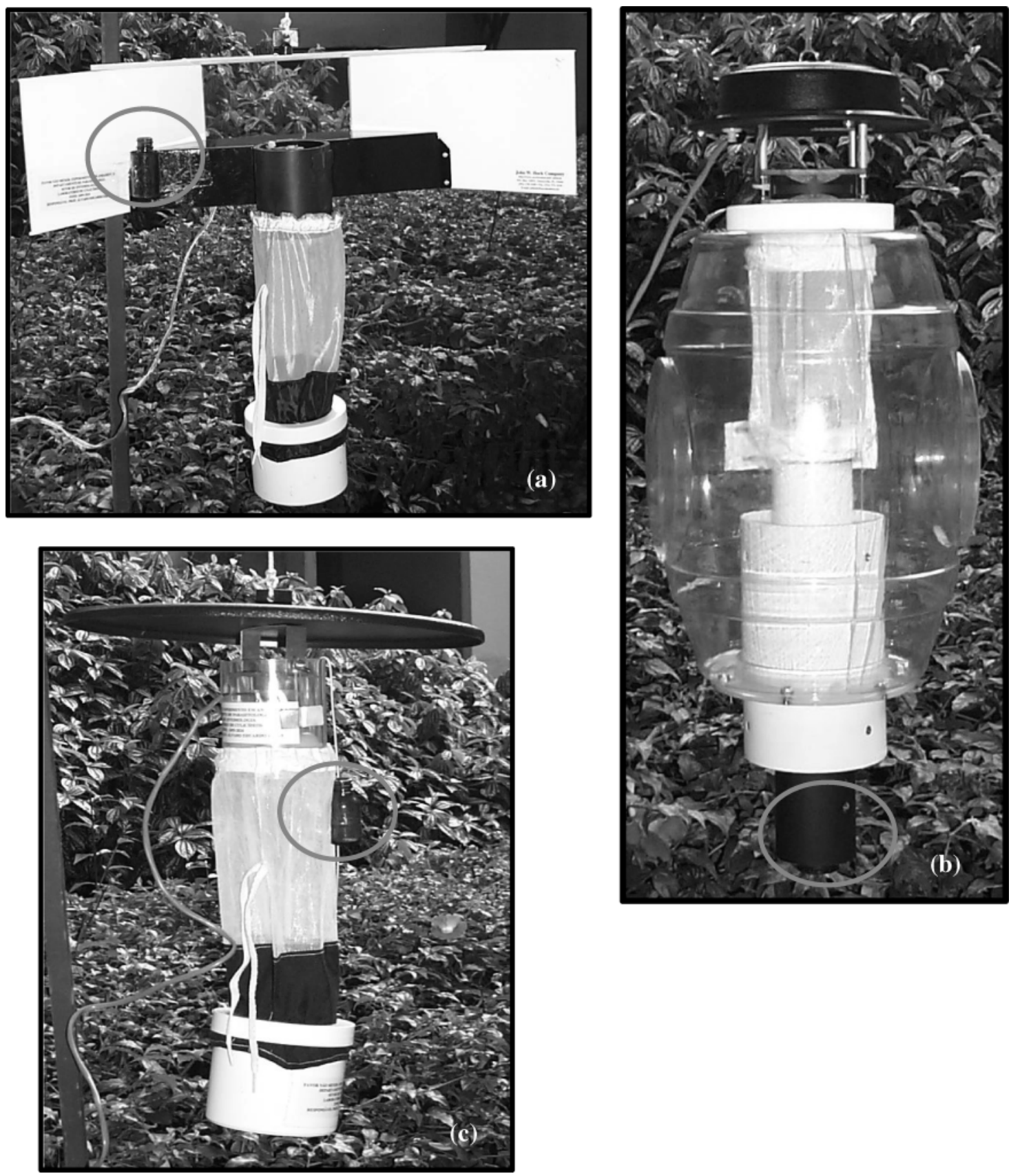

Fig. 1. Trap models showing release vial positions as indicated by circle: (a) Fay-Prince*, (b) CFG**, and (c) CDC.

Visual characteristics, such as size, color, and movement are important cues for diurnally active insects to orient toward a host (Eiras 2001). Thus, collection efficiency can be strongly influenced by trap design. The response of Ae. aegypti to visual stimuli has been shown. This species is significantly attracted by black color (Muir et al. 1992); to black and white patterns (Sippell and Brown 1953); and to yellow, orange, and red colors (Gilbert and
Gouck 1957). The capacity to reflect light (reflectance) also has an effect, and opaque materials are more attractive than transparent ones. Both FayPrince and CFG traps present a black and white contrast at the trap entrance. This contrast of colors could be responsible for the visual attraction of $A e$. aegypti.

These results show that a synthetic human odor blend can effectively attract Ae. aegypti in the lab- 

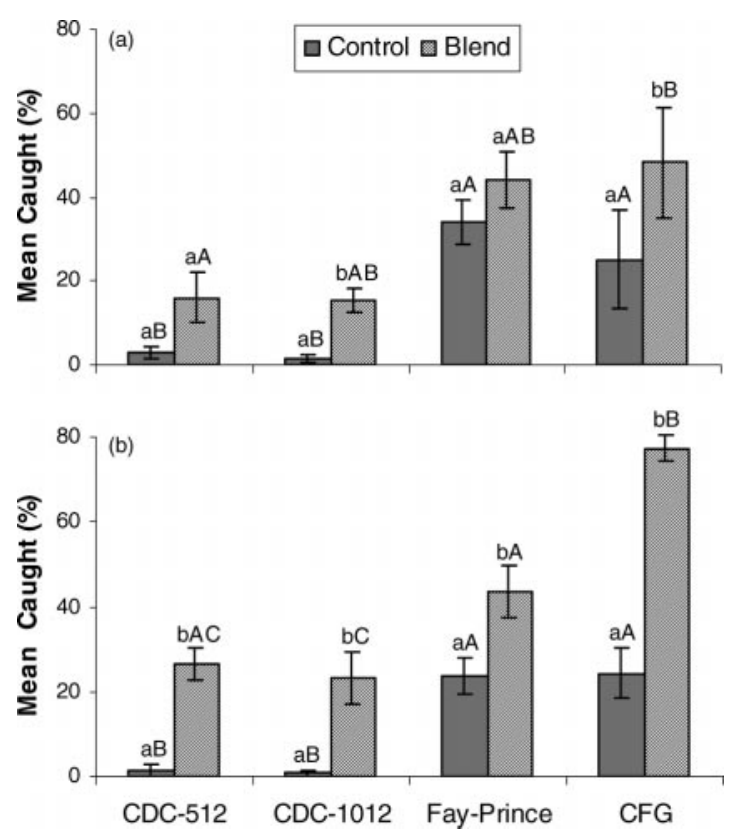

Fig. 2. Comparison of mean percentage of 20 Aedes aegypti female mosquitoes captured per trap type baited with (a) low (42.0 $\pm 2.3 \mathrm{mg} / \mathrm{h}, n=6)$ and (b) high (320.2 $\pm 10.7 \mathrm{mg} / \mathrm{h}, n=8$ ) release rates of human odor blend in laboratory tests. Traps without blend were used as controls. Small letters over bars indicate statistical differences or similarities between control and blend ( $t$-test), and capital letters compare the same treatment between traps (ANOVA, Tukey). Mean percentages with no letters in common are significantly different at $P<0.05$.

oratory, but further blend modifications and trap developments most likely will be needed before results such as this can be realized in the field, where many odor cues can compete and interfere with the experiment. The composition, ratio, and concentrations of chemical attractants in a blend can directly affect the efficacy of mosquito catches in baited traps. The blend used herein simulates human body odor to elicit host-seeking behavior in Ae. aegypti (Bernier et al. 2001, 2003). The abundance of the blend constituents is important because they can affect different phases of the host-seeking process, and different gas phase ratios will significantly alter the attraction to the blend. It is highly likely that the addition of 1 or more additional chemicals, alteration of ratios via changing abundances, or both might still be necessary to improve the blend.

Fay-Prince and CFG traps were found to be effective tools for sampling Ae. aegypti indoors (laboratory conditions) in the absence of human odors. Additional laboratory studies will be done to evaluate the performance of these traps against human odor. The CFG trap was more efficient than the Fay-Prince trap in its ability to capture Aedes aegypti; however, it is bulky and more expensive. Besides capture efficiency, factors such as ease of transport, operation, and price will need to be considered before an optimal trap can be chosen for an Ae. aegypti monitoring program.

This work was supported by Conselho Nacional de Desenvolvimento Científico e Tecnológico (CNPq) the Fundação Nacional de Saúde (Brazil). The traps were generously provided by the U.S. Department of Agriculture (USDA) and American Biophysics Co. (East Greenwich, RI).

\section{REFERENCES CITED}

Allan SA, Day JF, Edman JD. 1987. Visual ecology of biting flies. Ann Rev Entomol 32:297-316.

Bernier UR, Booth MM, Yost RA. 1999. Analysis of human skin emanations by gas chromatography/mass spectrometry. 1. Thermal desorption of attractants for the yellow fever mosquito (Aedes aegypti) from handled glass beads. Anal Chem 71:1-7.

Bernier UR, Kline DL, Barnard DR, Posey KH, Booth MM, Yost RA. 2001. Chemical composition that attract arthropods. U.S. Patent 6,267,953, Washington, DC: U.S. Patent and Trademark Office.

Bernier UR, Kline DL, Barnard DR, Schreck CE, Yost RA. 2000. Analysis of human skin emanations by gas chromatography/mass spectrometry. 2. Identification of volatile compounds that are candidate attractants for the yellow fever mosquito (Aedes aegypti). Anal Chem 72: 747-756.

Bernier UR, Kline DL, Posey KH, Booth MM, Yost RA, Barnard DR. 2003. Synergistic attraction of Aedes aegypti (L.) to binary blends of L-lactic acid and acetone, dichloromethane, or dimethyl disulfide. J Med Entomol 40:653-656.

Bernier UR, Kline DL, Schreck CE, Yost RA, Barnard DR. 2002. Chemical analysis of human skin emanations: comparison of volatiles from humans that differ in attraction of Aedes aegypti (Diptera: Culicidae). $J$ Am Mosq Control Assoc 18:186-195.

Bidlingmayer WL, Hem DG. 1980. The range of visual attraction and the effect of competitive visual attractants upon mosquito (Diptera: Culicidae) flight. Bull Entomol Res 70:321-342.

Bowen MF. 1991. The sensory physiology of host-seeking behavior in mosquitoes. Ann Rev Entomol 36:139-158.

Canyon DV, Hii JLK. 1997. Efficacy of carbon dioxide, 1-octen-3-ol, and lactic acid in modified Fay-Prince traps as compared to man-landing catch of Aedes aegypti. J Am Mosq Control Assoc 13:66-70.

Edman JD. 1979. Orientation of some Florida mosquitoes (Diptera:Culicidae) towards small vertebrates and carbon dioxide in the field. J Med Entomol 15:292-296.

Eiras AE. 2001. Mediadores químicos entre hospedeiros e insetos vetores de doenças médico-veterinárias. In: Vilela EF, Della Lucia TMC, eds. Feromonios de insetos. Biologia, química e emprego no manejo de pragas 2nd ed. Ribeirão Preto, SP: Holos Editora Ltda. p 99-112.

Eiras AE, Jepson PC. 1991. Host location by Aedes aegypti (Diptera: Culicidae): a wind tunnel study of chemical cues. Bull Entomol Res 81:151-160.

Eiras AE, Jepson PC. 1994. Responses of females Aedes aegypti (Diptera: Culicidae) to host odours and convection currents using an olfactometer bioassay. Bull Entomol Res 84:207-211. 
Fay RW, Prince WH. 1970. A modified visual trap for Aedes aegypti. Mosq News 30:20-23.

Gilbert IH, Gouck HK. 1957. Influence of surface color on mosquito landing rates. J Econ Entomol 50:678680.

Gillies MT, Wilkes TJ. 1974. The range of attraction of animal baits and carbon dioxide for mosquitoes (Diptera: Culicidae). Bull Entomol Res 63:573-581.

Kline DL. 1999. Comparison of two American Biophysics mosquito traps: the professional and a new counterflow geometry trap. J Am Mosq Control Assoc 15:276-282.

Mboera LEG, Knols BGJ, Braks MAH, Takken W. 2000 Comparison of carbon dioxide-baited trapping systems for sampling outdoor mosquito populations in Tanzania. Med Vet Entomol 14:257-263.

Muir LE, Kay BH, Thorne MJ. 1992. Aedes aegypti (Diptera: Culicidae) vision: response to stimuli from the optical environment. J Med Entomol 29:445-450.

Posey KH, Schreck CE. 1981. An airflow apparatus for selecting female mosquitoes for use in repellent and attraction studies. Mosq News 41:566-568.

Sastry SD, Buck KT, Janák J, Dressler M, Preti G. 1980. Volatiles emitted by humans. In: Wiley J, ed. Supplementary Volume to Biochemical Applications of Mass Spectometry. New York: Interscience. p 1085-1129.

Service MW. 1993. Mosquito ecology-field sampling methods 2nd ed. London: Chapman and Hall.

Schreck CE, Smith N, Carlson DA, Price GD, Haile D, Godwin DR. 1981. A material isolated from human hands that attracts female mosquitoes. J Chem Ecol 8: 429-438.

Sippell WL, Brown AW. 1953. Studies of the responses of the female Aedes mosquito. Part V. The role of visual factors. Bull Entomol Res 43:567-574.

Sudia WD, Chamberlain RW. 1962. Battery-operated light trap, an improved model. Mosq News 22:126-129.

Wilinson L, Hill M, Welna JP, Birkenbuel GK. 1998. Systat statistics 2nd ed. Evanston, IL: Systat Inc.

Wilton DP, Fay RW. 1972. Air flow direction and velocity in light trap design. Entomol Exp Appl 15:377-386. 